\title{
Kielland's forceps: role of antenatal factors in prediction of use
}

\author{
DAVID K JAMES, MALCOLM L CHISWICK
}

British Medical fournal, 1979, 1, 10-11

\section{Summary and conclusions}

The association between certain antenatal factors and the use of Kielland's forceps was analysed retrospectively in liveborn singleton births that occurred at this hospital between January and December 1976. Factors significantly associated with the use of Kielland's forceps were primiparity, short maternal stature, induction of labour, late engagement of the fetal head, low ratio of maternal height to fetal occipitofrontal head circumference, slow dilatation of the cervix in labour, and the use of epidural analgesia in labour.

The findings support a contribution of cephalopelvic disproportion in the genesis of malposition, and when associated with slow dilatation of the cervix delivery should be expedited. Long-term follow-up studies are needed, however, before the role of caesarean section in reducing morbidity associated with malposition can be properly assessed.

\section{Introduction}

In our accompanying paper in this issue (p 7) we drew attention to the relatively high neonatal mortality and morbidity rates associated with the use of Kielland's forceps. Fetal asphyxia was associated with an increased incidence of neonatal complications; other factors, including certain indices of maternal and infant size, interval between engagement of the fetal head and the onset of labour, and the speed of cervical dilatation, were unhelpful in predicting the occurrence of neonatal complications. The prompt recognition of adverse antenatal and intrapartum events is a prerequisite for good perinatal care, and in this paper we examine certain factors that might be useful in anticipating the use of Kielland's forceps. If forewarned of the likelihood that labour will culminate in the use of Kielland's forceps, increased vigilance or in certain cases resort to caesarean section might reduce neonatal mortality and morbidity.

\section{Patients and methods}

The study group comprised 86 consecutive liveborn singleton babies delivered by Kielland's forceps or emergency caesarean section after attempted delivery with Kielland's forceps at this hospital between January and December 1976. Their antenatal and intrapartum management is described in our accompanying paper. The following data were documented: maternal age, parity, and height; infant's birth weight and occipitofrontal head circumference; whether labour was induced, and whether epidural analgesia was used during labour; interval between engagement of the fetal head and onset of labour; and time taken for the cervix to dilate from 4 to $7 \mathrm{~cm}$ and from 7 to $10 \mathrm{~cm}$.

St Mary's Hospital, Whitworth Park, Manchester M13 0JH

DAVID $\mathrm{K}$ JAMES, $\mathrm{MB}, \mathrm{DCH}$, senior house officer in obstetrics and neonatal

paediatrics (now registrar in obstetrics and gynaecology, Wythenshawe

Hospital, Manchester M23 9LT)

MALCOLM L CHISWICK, MD, MRCP, consultant neonatal paediatrician
Corresponding data were analysed in a group of 86 liveborn singleton babies born by spontaneous vaginal delivery (control group). Their characteristics are described in our accompanying paper.

The study and control groups were matched for maternal age and parity and whether labour was induced or spontaneous. To determine the influence of these factors on the incidence of Kielland's forceps delivery the study group was compared with all 4095 other babies born alive at the hospital during the same year.

Student's $t$ test was used to compare mean values between groups, and the $\chi^{2}$ test with Yates's correction to compare frequencies between groups.

\section{Results}

The age distribution of mothers in the study group was similar to that of mothers of all other babies born alive at the hospital during the same year. Sixty-five mothers in the study group $(75.6 \%)$ were primigravidae compared with 1425 mothers of all other babies $(34.8 \%)(P<0.001)$. Forty-three mothers in the study group $(50.0 \%)$ had their labours induced, whereas the induction rate for all other births was $24.0 \%(P<0.001)$.

Maternal and infant size-The mean birth weight and occipitofrontal head circumference of babies in the study and control groups were similar (table I). Mean maternal height in the study group (159.8 \pm SD

TABLE I-Indices of maternal and baby size in study and control groups (means \pm $S D)$

\begin{tabular}{|c|c|c|}
\hline & $\begin{array}{l}\text { Study group } \\
(\mathrm{n}=86)\end{array}$ & $\begin{array}{l}\text { Controls } \\
(\mathrm{n}=86)\end{array}$ \\
\hline $\begin{array}{lll}\text { Maternal height }(\mathrm{cm}) & \ldots & \ldots \\
\text { Birth weight }(\mathrm{g})\end{array}$ & $\begin{array}{l}159 \cdot 8 \pm 5 \cdot 5 \\
3316 \pm 464\end{array}$ & $\begin{array}{c}162 \cdot 2 \pm 6 \cdot 5^{*} \\
3306 \pm 499\end{array}$ \\
\hline $\begin{array}{l}\text { Occipitofrontal head circumference } \\
\text { (cm) }\end{array}$ & $35 \cdot 2 \pm 1 \cdot 4$ & $35 \cdot 0 \pm 1 \cdot 3$ \\
\hline $\begin{array}{l}\text { weight } \\
\text { Ratio of maternal height to }\end{array}$ & $4 \cdot 9 \pm 0 \cdot 6$ & $5 \cdot 1 \pm 0 \cdot 8$ \\
\hline occipitofrontal head circumference & $4.5 \pm 0.2$ & $4 \cdot 7 \pm 0 \cdot 2+$ \\
\hline
\end{tabular}

$* \mathbf{P}<0.01$

$+\mathrm{P}<0.001$

TABLE II-Rates of cervical dilatation in study and control groups

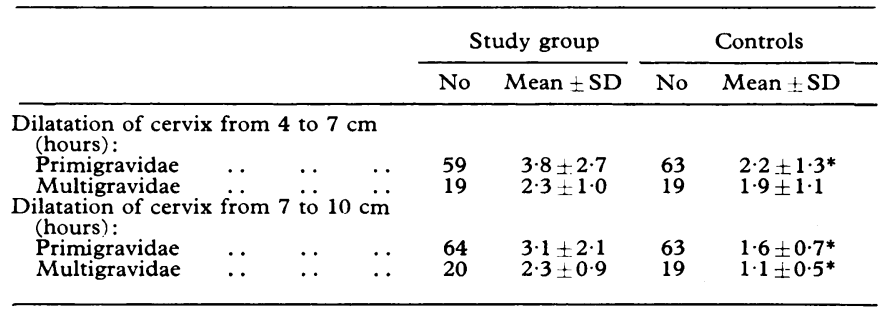

$* \mathrm{P}<0.001$

$5.5 \mathrm{~cm})$, however, was lower than that in the control group $(162 \cdot 2 \pm 6.5$ $\mathrm{cm})(P<0.01)$. The mean ratio of maternal height to birth weight was similar in the study and control groups, whereas the mean ratio of maternal height to occipitofrontal head circumference was significantly smaller in the study group $(4.5 \pm 0 \cdot 2)$ than in the control group $(4 \cdot 7 \pm 0 \cdot 2)(\mathbf{P}<0.001)$.

Engagement of fetal head and cervical dilatation-The mean interval between engagement of the fetal head and the onset of labour was significantly shorter in the study group than in the controls. This 
difference was maintained even when primigravidae and multigravidae were considered separately. The respective mean intervals in the 130 primigravidae in the two groups were $1.32 \pm \mathrm{SD} 1.63$ and $2.2 \pm 2.0$ weeks $(P<0.001)$, and in the 42 multigravidae $0.82 \pm 1.92$ and $1.7 \pm 1.7$ weeks $(P<0.001)$. In primigravidae in the study group the mean time taken for the cervix to dilate from 4 to $7 \mathrm{~cm}(3.8 \pm 2 \cdot 7$ hours) was longer than in primigravidae who delivered spontaneously $(2 \cdot 2 \pm 1 \cdot 3$ hours) $(P<0.001)$. The mean time taken for the cervix to dilate from 7 to $10 \mathrm{~cm}$ was longer in both primigravidae and multigravidae in the study group than in women who delivered spontaneously $(P<0.001-$ table II). Partograms showing the speed of cervical dilatation from 7 to $10 \mathrm{~cm}$ in the study and control groups are given in the figure.

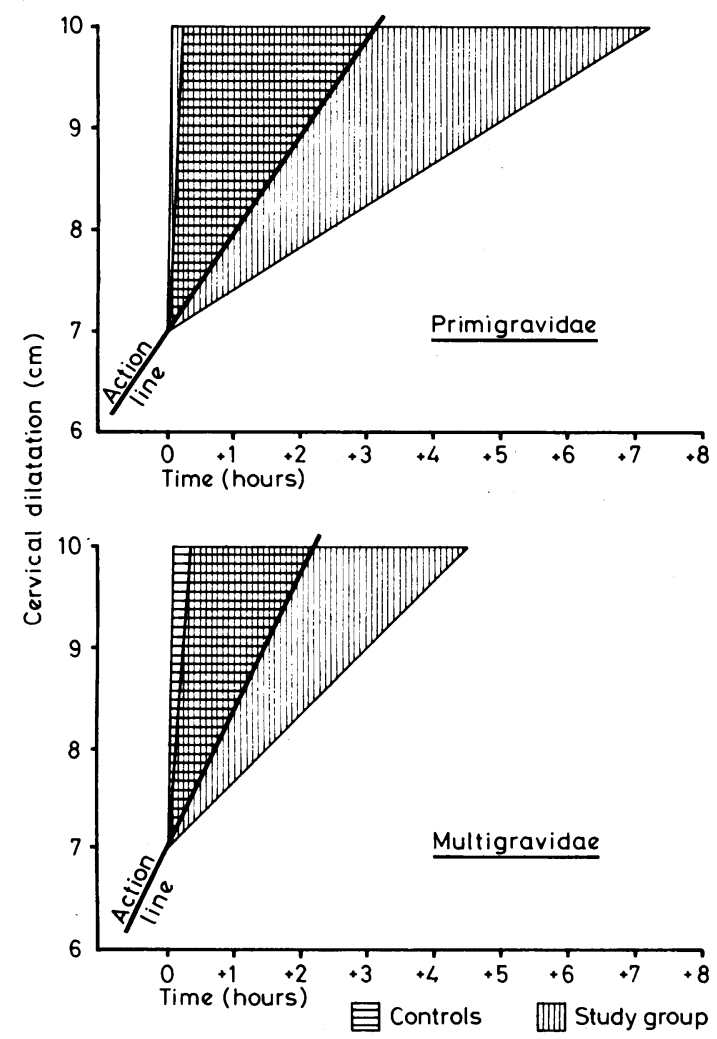

Rates of cervical dilatation from 7 to $10 \mathrm{~cm}$ in primigravidae and multigravidae in study and control groups. Normal ranges (mean $\pm 2 S D$ ) shown by respective shaded areas. Action line is upper limit of normal range of time (mean +2 $\mathrm{SD})$ for spontaneous vertex deliveries.

Epidural anaesthesia was used in 58 mothers in the study group $(67 \cdot 4 \%)$ as compared with only $16(18.6 \%)$ of the mothers who had normal deliveries $(P<0.001)$.

\section{Discussion}

Baird ${ }^{1}$ observed a relation between persistent occipitoposterior position of the fetal head and short maternal stature. Occipitoposterior position is also well recognised as one of the commonest causes of late engagement of the fetal head. ${ }^{2}$ Our finding of an association between primiparity, short maternal stature, late engagement of the fetal head, and delivery by Kielland's forceps serves to underline traditional obstetric concepts. The findings support the contributory role of cephalopelvic disproportion in the genesis of a persistent occipitoposterior position. Whereas the mean birth weight and occipitofrontal head circumference of babies born by Kielland's forceps and those born spontaneously were similar, the mean ratio of maternal height to occipitofrontal head circumference was smaller when delivery was by Kielland's forceps. It is significant that the mean ratio of maternal height to birth weight was similar in the two groups.

The observed relation between induction of labour and delivery by Kielland's forceps is probably not causal: diverse obstetric and socioeconomic factors usually operate in any group of pregnancies culminating in induced labour, and such factors might indirectly be associated with a relatively high incidence of malposition of the fetal head. The use of induction of labour continues to be debated, ${ }^{3}$ and the association between induction and the use of Kielland's forceps emphasises that there is no room for complacency in the selection and management of patients for induction of labour.

Davidson $e t$ al ${ }^{4}$ suggested that if the cervix took longer than two hours to dilate from 7 to $10 \mathrm{~cm}$ delivery was likely to be difficult. The partograms that were constructed on the basis of our findings may be used as standards against which the speed of cervical dilatation may be assessed in individual labours when the fetal head is not in the occipitoanterior position. When serial vaginal examinations show that the speed of cervical dilatation is abnormally slow (to the right of the action lines on the partograms) it is most unlikely that spontaneous rotation of the fetal head will occur. Abnormally slow cervical dilatation per se seems not to influence the occurrence of neonatal complications, whereas fetal asphyxia is the single most important factor promoting neonatal morbidity in association with delivery by Kielland's forceps (see our accompanying paper).

Delayed cervical dilatation associated with malposition should therefore lead to continuous fetal heart rate monitoring combined with measurements of fetal scalp blood $\mathrm{pH}$ so that fetal asphyxia can be promptly recognised and delivery expedited. It is speculative whether even in the absence of fetal asphyxia malposition associated with abnormally slow cervical dilatation is an indication for caesarean section. If caesarean section were carried out in all such cases the rate for the operation at this hospital would increase by about only one per cent, and three neonatal deaths in 1976 associated with tentorial tears might have been averted. Long-term follow-up studies are needed before the role of caesarean section in preventing morbidity associated with malposition can be properly assessed. In the absence of fetal asphyxia abnormal neurological behaviour was observed in about $14 \%$ of babies born by Kielland's forceps (see our accompanying paper), and all of these babies were clinically normal on discharge from the maternity unit.

The higher incidence of the use of epidural analgesia in mothers delivered with Kielland's forceps than in mothers who delivered spontaneously would be expected if persistent occipitoposterior position of the fetal head generates a more painful and prolonged labour than the occipitoanterior position. Hoult $e t a l,{ }^{5}$ however, suggested a causal relation between epidural analgesia and malposition. They postulated that epidural analgesia decreases tone in the muscles of the pelvic floor and that the occiput is less likely to rotate anteriorly when it is pushed against a relaxed levator ani. If this is so, epidural analgesia should be avoided in the presence of a combination of other factors that are known to be associated with an increased incidence of malposition such as primiparity, short maternal stature, and late engagement of the fetal head. The precise relation between the use of epidural analgesia and the incidence of malposition, however, remains controversial. ${ }^{6-8}$

\section{References}

1 Baird, D, Lancet, 1949, 1, 1079.

2 Donald, I, Practical Obstetric Problems, 4th edn, ch 18. London, LloydLuke, 1969.

${ }^{3}$ British Medical fournal, 1976, 1, 729.

4 Davidson, A C, et al, British fournal of Obstetrics and Gynaecology, 1976, 83, 279.

${ }^{5}$ Hoult, I J, MacLennan, A H, and Carrie, L E S, British Medical fournal, 1977, 1, 14.

${ }^{6}$ Potter, N, and MacDonald, R D, Lancet, 1971, 1, 1031.

7 Studd, J, in Management of Labour, ed $\mathrm{R} W$ Beard et al, $\mathrm{p}$ 179. London, Royal College of Obstetricians and Gynaecologists, 1975.

${ }^{8}$ McQueen, J, and Mylrea, L, British Medical fournal, 1977, 1, 640. 